\title{
O Paradigma Reflexivo e as Diversas Jnterpretações dos Formadores de Professores de Inglês
}

\author{
Nalini Iara Leite ARRUDA ${ }^{1}$ \\ Telma GIMENEZ ${ }^{2}$ \\ Universidade Estadual de Londrina
}

Resumo: $\mathrm{Na}$ atualidade, pode se considerar o paradigma reflexivo como dominante na área de formação de professores de inglês. Isto se reflete na literatura e em pesquisas mais recentes. Contudo, são diversos os entendimentos do que seja reflexão, quadro este já apontado por vários pesquisadores. $\mathrm{Na}$ grande quantidade de atividades rotuladas reflexivas residem também divergências e convergências sobre o que significa formar professores com esta abordagem. Este trabalho tem por objetivo mapear os significados de reflexão na literatura de formação de professores, como parte integrante do subprojeto de iniciação científica "O ensino reflexivo na formação de professores de inglês".

Palavras-chave: reflexão, formação de professores

\begin{abstract}
Nowadays, the reflective approach can be considered the predominant paradigm in the education of English language teachers. This is revealed in the literature and recent research. However, there are several understandings of what reflection means, and this has already been pointed out by researchers. Many points of convergence and divergence coexist in the great quantity of activities dubbed "reflective". This paper aims at mapping out the meanings of reflection in the literature of teacher education, as part of a project entitled "Reflective teaching in the education of English language teachers".
\end{abstract}

Key words: reflection, teacher education

\footnotetext{
${ }^{1}$ Bolsista de Iniciação Científica (CNPq)

${ }^{2}$ Agradeço ao CNPq a concessão de bolsa produtividade, que viabilizou a realização desta pesquisa.
} 


\section{Introdução}

A formação de professores tem se tornado um importante tema para pesquisas na área de Lingüística Aplicada. São vários os trabalhos que se ocupam dos estudos de programas de educação de professores tanto em nível pré-serviço como na fase em serviço. O paradigma dominante desses programas é o reflexivo. No entanto, o termo esconde uma variedade de interpretações. Este é um fenômeno já apontado por vários autores (e.g. Magalhães, 1998; Loughran, 2002; Zeichner, 1994; Pimenta, 2002, Ghedin, 2002, dentre outros).

Este trabalho é resultado do projeto de Iniciação Científica intitulado "O ensino reflexivo na formação de professores de inglês", integrante do projeto "Os sentidos da reflexão para formadores de professores de inglês". Neste projeto procuramos identificar as diferentes interpretações postuladas por pesquisadores acerca do termo reflexão, tendo em vista a diversidade de entendimentos na literatura que trata dos programas de formação de professores. Assim, o termo é apropriado por educadores e instituições com os mais diversos objetivos que justificam a implementação dessa prática.

Além da pesquisa na literatura, procuraremos também verificar de que modo um grupo de formadores entende essa abordagem e como a vêm colocando em prática. Este trabalho, contudo, abordará apenas a revisão bibliográfica realizada até o momento. O levantamento foi feito junto a periódicos nacionais e estrangeiros constantes no portal de periódicos da CAPES, nas áreas de Educação, Letras e Lingüística, abrangendo o período 1998-2003. No cenário nacional foram consultadas as revistas Contexturas (1 a 5), a Revista Brasileira de Lingüística Aplicada (2000-2002), Trabalhos em Lingüística Aplicada (1998-2002) e the ESPecialist (1998-2002). Foram também pesquisadas as coletâneas organizadas por Almeida Filho (1999); Leffa (2001) e Gimenez (2002).

\section{Entendimentos de 'Reflexão'}

Um dos autores mais influentes na área de reflexão é Donald Schön $(1983,1987)$. Para Schön, o pensamento teórico não 
poderia "dirigir" a prática dos profissionais: a solução para as questões profissionais estaria na própria prática, isto é, no conhecimento gerado pela prática e a reflexão na e sobre a ação. Assim, Schön criou a "epistemologia da prática", que está "implícita no processo artístico, intuitivo que alguns profissionais trazem para situações de incerteza, instabilidade, excepcionalidade, e valor conflitual" (SCHÖN, 1983, p. 49). A reflexão-na-ação consiste num instante rápido de reflexão, no qual o profissional toma decisões a respeito de situações repentinas no momento em que está trabalhando. É o caso do professor em sala de aula, o qual está o tempo todo interagindo com os alunos, improvisando resoluções para momentos de surpresa (alguma pergunta inesperada, conversas entre alunos, outro aluno que fez o exercício de maneira diferente da que foi solicitada). Assim, ele toma decisões rápidas para solucionar os problemas que surgem simultaneamente na classe. Já a reflexão sobre a reflexão-na-ação baseia-se na reorganização ou na reconstrução da experiência na ação, que leva a um novo entendimento da situação da prática. Consiste num olhar retrospectivo sobre a aula, sobre as ações e observações, descrevendo-a para clarear as questões surgidas durante o seu desenvolvimento.

Portanto, a reflexão-na-ação e a reflexão sobre a reflexãona-ação envolvem uma forma de experimentação na qual os profissionais tentam criar um significado do aspecto problemático da situação da prática através de "mapeamento do problema" (problem setting) e "resolução do problema" (problem solving). Dessa forma, a reflexão engaja os profissionais em uma "conversa" com a situação problemática. Em síntese, o conceito de reflexão para Schön é uma parte integral de sua visão de conhecimento profissional.

Outro pesquisador bastante influente nessa área, Zeichner (1994) tem uma visão um pouco mais ampla e distingue níveis de reflexão de acordo com a intervenção que ela promove: reflexão técnica, prática ou crítica. A reflexão técnica se concentra na eficácia e eficiência dos meios usados para os fins educacionais que não são questionados. O segundo nível descrito por Zeichner é reflexão prática, cuja tarefa é explicar e tornar mais claros os pressupostos que embasam a atividade pedagógica e avaliar a adequação dos fins educacionais almejados pelas ações. Já a reflexão crítica incorpora valores morais e éticos ao questionar se objetivos, atividades e experiências educacionais são mais socialmente 
justos. O professor que reflete criticamente avalia o contexto em que a escola e os alunos estão envolvidos, unindo suas questões morais e éticas para esclarecer as ações e promover mudanças que vão além da sala de aula. De acordo com Zeichner (1994, p. 12):

[...] critical reflection would extend a concern with the worth of educational goals and how effectively they are being accomplished, to a consideration of such issues as who is benefiting from the successful accomplishment of those ends, all students or just some.

Grimmett (1988) propõe três categorizações para os modos como reflexão pode ser concebida. A primeira trata da reflexão como ponderação sobre a ação - ponderação que levaria a ações deliberadas e conscientes, geralmente para aplicar resultados de pesquisas ou teorias educacionais. Neste caso, o conhecimento derivado de pesquisa direciona a prática de professores.

A segunda concepção postula uma visão de reflexão como deliberação e escolha entre versões rivais de "bom ensino", consideração de eventos educacionais em contexto e de conseqüências de determinados cursos de ação, tomadas a partir dessas visões de bom ensino. O conhecimento derivado de pesquisas serve para informar a prática de professores.

O terceiro conjunto de concepções vê a reflexão como reconstrutora da experiência, cujo objetivo é identificar novas possibilidades de ação. Essa reorganização ou reconstrução da experiência pode levar a: i) novos entendimentos de situações; ii) novos entendimentos de si mesmo como professor ou do meio educacional, ou, ainda, seguindo uma tradição crítica; iii) novos entendimentos a respeito de pressupostos sobre o ensino. Nesta visão, a reflexão permite aos profissionais articularem uma consciência madura sobre sua prática e se emanciparem das distorções sociais, políticas e culturais que frustram e limitam seu entendimento. A reflexão crítica começa com perguntas do tipo "para que fins, em nome de quem esse conhecimento está sendo usado?"

Smyth (1992), baseado em Paulo Freire, propõe quatro etapas pelas quais o professor poderia desenvolver a reflexão crítica: 
descrever, informar, confrontar e reconstruir. Na primeira etapa, o professor descreve o que faz. Para isso, ele pode usar um diário, no qual descreve regularmente eventos concretos ocorridos durante sua prática, para melhor entendê-la e, posteriormente transformá-la. É neste momento que ele se pergunta: "O que eu faço?". A descrição leva ao segundo estágio, informar, que envolve uma busca dos princípios que embasam (conscientemente ou não) as ações em sala de aula. Sua prática está ligada a teorias formais que a sustentam e, ao informá-la, o professor conseguirá entendê-las melhor. Neste estágio ele procura responder à pergunta: "Qual o significado das minhas ações?". É no confrontar que o professor submete as teorias formais que fundamentam as ações a algum tipo de questionamento. A partir deles, os educadores passam a entender como as forças sociais e institucionais além de suas salas de aula e da escola, influenciam seu modo de agir e pensar. Assim, o confrontar remete a questionamentos tais como "Quem tem poder em minha sala de aula?"; "A que interesses minha prática está servindo?”; “Acredito nesses interesses ou apenas os reproduzo?”. O quarto estágio, o de reconstruir, está ligado à transformação da prática com vistas à emancipação. Através do entendimento conduzido pelas etapas anteriores, o educador passa a encontrar alternativas para suas ações e reconstruí-las, adquirindo maior controle sobre sua prática através de auto-gerenciamento, autoregulação e auto-responsabilidade.

Vários trabalhos têm se utilizado do referencial de Smyth para desenvolvimento da reflexão crítica (e.g. Magalhães, 2002; Liberali \& Zyngier, 2000; Cruz \& Reis, 2002; Loughran, 2002). Na seção seguinte serão apresentados alguns dos trabalhos realizados em contexto nacional.

\section{Pesquisas sobre Reflexão na Formação de Professores de Línguas}

O quadro abaixo traz publicações de alguns pesquisadores brasileiros na área de língua estrangeira, com os conceitos de reflexão, autores que serviram de base para os estudos e as estratégias utilizadas para promoção da reflexão, assim como contextos de formação em que foram empregadas. 


\begin{tabular}{|c|c|c|c|c|}
\hline FONTE & $\begin{array}{c}\text { CONCEITOS } \\
\text { DE REFLEXÃO }\end{array}$ & $\begin{array}{c}\text { AUTORES NOS } \\
\text { QUAIS SE } \\
\text { BASEIAM }\end{array}$ & $\begin{array}{c}\text { MODOS/ } \\
\text { ESTRATÉGIAS } \\
\text { DE SE } \\
\text { PROMOVER } \\
\text { REFLEXÃO }\end{array}$ & $\begin{array}{l}\text { CONTEXTO } \\
\text { DE } \\
\text { FORMAÇÃO }\end{array}$ \\
\hline Monteiro (1996) & $\begin{array}{l}\text { União equilibrada } \\
\text { entre o modelo } \\
\text { artístico (craft model) e } \\
\text { o modelo de } \\
\text { aplicação de ciência } \\
\text { (applied science model). }\end{array}$ & Wallace (1991) & \begin{tabular}{|l|} 
Presença de um \\
especialista da \\
área junto com \\
professores. \\
Reflexão solitária \\
- possíveis \\
instrumentos: \\
- listas, como as \\
sugeridas por \\
Woodward \\
(1991): \\
propostas de \\
comportamentos \\
desejáveis para o \\
professor em \\
sala (e.g. attract \\
attention, praise, \\
explain things). \\
Matriz de Nunan \\
(1990) - para \\
planejar e avaliar \\
tarefas \\
Roteiros (Doff, \\
1995): lista de \\
perguntas que o \\
professor faz \\
após dar \\
atividades \\
(reading, writing, \\
testing - aos \\
alunos).
\end{tabular} & $\begin{array}{l}\text { Professores em } \\
\text { serviço. }\end{array}$ \\
\hline $\begin{array}{l}\text { Assis-Peterson } \\
(1998 / \\
1999)\end{array}$ & $\begin{array}{l}\text { Tentar entender o } \\
\text { que se faz, como e } \\
\text { porque o faz, assim } \\
\text { como entender o } \\
\text { que e porque os } \\
\text { alunos aprendem. }\end{array}$ & $\begin{array}{l}\text { Richards \& } \\
\text { Lockhart (1994) }\end{array}$ & \begin{tabular}{|l|} 
Perguntas que o \\
professor faz a si \\
mesmo, extraídas \\
de Richards \& \\
Lockhart: \\
- Não faz \\
proposta \\
concreta de \\
como e quando \\
essas perguntas \\
poderão ser \\
feitas
\end{tabular} & $\begin{array}{l}\text { Não traz relatos de } \\
\text { resultados de } \\
\text { pesquisa. Texto } \\
\text { que reforça a idéia } \\
\text { de que reflexão é } \\
\text { importante. }\end{array}$ \\
\hline $\begin{array}{l}\text { Almeida Filho } \\
\text { (1999) }\end{array}$ & \begin{tabular}{|l|} 
Análise de \\
abordagem \\
Tomada de \\
consciência de \\
como se ensina e \\
porque se ensina \\
desta maneira com \\
que resultados.
\end{tabular} & & $\begin{array}{l}\text { - Pesquisa } \\
\text { etnográfica sobre } \\
\text { própria prática }\end{array}$ & $\begin{array}{l}\text { Não traz relatos de } \\
\text { pesquisa. Reforça } \\
\text { idéia de que } \\
\text { professor precisa } \\
\text { tomar consciência } \\
\text { de sua prática, } \\
\text { para promover } \\
\text { mudanças. }\end{array}$ \\
\hline
\end{tabular}




\begin{tabular}{|c|c|c|c|c|}
\hline \begin{tabular}{|l} 
Liberali \& \\
Zyngier (2000)
\end{tabular} & Reflexão crítica & $\begin{array}{l}\text { Van Manen (1977) } \\
\text { Smyth (1992) }\end{array}$ & $\begin{array}{ll}- & \text { Reflexão crítica - } \\
- & \text { descrever } \\
- & \text { informar } \\
- & \text { confrontar } \\
- & \text { reconstruir } \\
\end{array}$ & $\begin{array}{l}\text { Professores em } \\
\text { fase pré-serviço. }\end{array}$ \\
\hline Liberali (2002) & $\begin{array}{l}\text { Reflexão crítica } \\
\text { Pesquisa crítica, } \\
\text { professor } \\
\text { investigador da } \\
\text { própria prática para } \\
\text { que se promova } \\
\text { uma mudança em } \\
\text { níveis individual, } \\
\text { escolar e social. }\end{array}$ & $\begin{array}{l}\text { Kemmis, (1987) } \\
\text { Bredo e Feinberg } \\
(1982) \\
\text { Smyth (1992) } \\
\text { Stake (1987) }\end{array}$ & \begin{tabular}{|ll} 
- & Reflexão crítica - \\
Smyth (1992) \\
- & Pesquisa \\
colaborativa \\
- & Ferramenta \\
& lingüística.
\end{tabular} & $\begin{array}{l}\text { Professores em } \\
\text { serviço. }\end{array}$ \\
\hline $\begin{array}{l}\text { Vieira-Abrahão } \\
(2000 / \\
2001, \\
2002)\end{array}$ & \begin{tabular}{|l|} 
Construir \\
conscientemente \\
uma forma de \\
ensino; pensar \\
sobre as influências \\
que a prática \\
pedagógica \\
desenvolvida exerce \\
na formação da \\
sociedade e do \\
aluno.
\end{tabular} & $\begin{array}{l}\text { Barllett (1990) } \\
\text { Wallace (1991) }\end{array}$ & \begin{tabular}{|ll}
- & Diários \\
& introspectivos \\
- & Gravação em \\
& áudio e vídeo \\
& seguidos por \\
& transcrições ou \\
& sessões de \\
& visionamento \\
- & Discussão em \\
grupo & Pesquisa-ação \\
individual ou \\
colaborativa.
\end{tabular} & $\begin{array}{l}\text { Professores em } \\
\text { fase pré-serviço. }\end{array}$ \\
\hline Telles (2002) & $\begin{array}{l}\text { Componentes do } \\
\text { conhecimento } \\
\text { pessoal prático } \\
\text { Imagens, regras e } \\
\text { princípios. }\end{array}$ & $\begin{array}{l}\text { Connely \& } \\
\text { Clandinin (1990) }\end{array}$ & \begin{tabular}{|l} 
Pesquisa \\
narrativa \\
Instrumentos de \\
coleta das \\
historias dos \\
professores: \\
histórias, anais e \\
crônicas, \\
fotografias, \\
entrevistas, \\
diários, cartas, \\
etc. \\
Apresentação \\
oral das \\
narrativas pelo \\
pesquisador e \\
professores \\
gravadas em \\
áudio, \\
transcrição das \\
narrativas, \\
tematização das \\
transcrições, \\
redação das \\
narrativas pelos \\
professores.
\end{tabular} & $\begin{array}{l}\text { Professores em } \\
\text { serviço. }\end{array}$ \\
\hline
\end{tabular}

SIgNum: Estud. Ling., Londrina, n. 7/2, p. 29-41, dez. 2004 


\begin{tabular}{|c|c|c|c|c|}
\hline \begin{tabular}{|l} 
Magalhães \\
$(2002)$
\end{tabular} & \begin{tabular}{|l|} 
"Reorganização e \\
reconstrução de \\
práticas que possam \\
conduzir a novas \\
compreensões de \\
um contexto de \\
ação particular visto \\
como problemático \\
para um \\
participante da \\
interação" \\
O “professor como \\
um profissional \\
crítico e reflexivo \\
envolve uma \\
rediscussão dos \\
papeis \\
tradicionalmente \\
atribuídos ao \\
professor, aos \\
alunos, ao livro \\
didático". \\
\end{tabular} & \begin{tabular}{|l} 
Dialogia de \\
Bakhtin, \\
Ação comunicativa \\
de \\
Habermas(1982), \\
Conceito de ensino- \\
aprendizagem e \\
desenvolvimento de \\
Vigotski. \\
Colter (1999)
\end{tabular} & 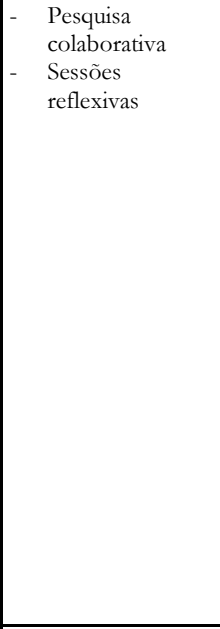 & $\begin{array}{l}\text { Professores em } \\
\text { serviço. }\end{array}$ \\
\hline Castro (2002) & $\begin{array}{l}\text { Reconstrução das } \\
\text { escolhas } \\
\text { instrucionais } \\
\text { evidenciadas em } \\
\text { planos de aula }\end{array}$ & \begin{tabular}{|l|} 
Linguagem \\
reorganiza formas \\
de pensamento que \\
dão lugar a novas \\
formas de ação
\end{tabular} & $\begin{array}{l}\text { Análise de planos } \\
\text { apresentados por } \\
\text { professores em } \\
\text { curso de extensão. }\end{array}$ & $\begin{array}{l}\text { Professores em } \\
\text { serviço }\end{array}$ \\
\hline Freitas (2002) & $\begin{array}{l}\text { Explicar a própria } \\
\text { prática. } \\
\text { Conscientização do } \\
\text { modo de ensinar e } \\
\text { informação de sua } \\
\text { prática e efeitos } \\
\text { causados nos } \\
\text { alunos. } \\
\end{array}$ & $\begin{array}{l}\text { Prabhu (1990) } \\
\text { Gebhard (1992) }\end{array}$ & \begin{tabular}{|l} 
Auto- \\
investigação \\
(gravação da \\
própria aula)
\end{tabular} & $\begin{array}{l}\text { Professores em } \\
\text { fase pré-serviço. }\end{array}$ \\
\hline $\begin{array}{l}\text { Cruz \& Reis } \\
(2002)\end{array}$ & $\begin{array}{l}\text { Recontar a própria } \\
\text { pratica: explicar, } \\
\text { informar e } \\
\text { questionar. } \\
\end{array}$ & Smyth (1992) & 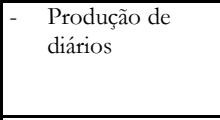 & $\begin{array}{l}\text { Professor em } \\
\text { serviço. }\end{array}$ \\
\hline Cristóvão (2002) & \begin{tabular}{|l|} 
Transformação. \\
"Modificação do \\
contexto e das \\
interações sociais \\
que nele se \\
desenvolvem" \\
Re-elaboração das \\
propostas e \\
mudança da prática. \\
\end{tabular} & $\begin{array}{l}\text { Chantraine- } \\
\text { Deniailly (1995) } \\
\text { Agir comunicativo } \\
\text { (Habermas, 1987) }\end{array}$ & 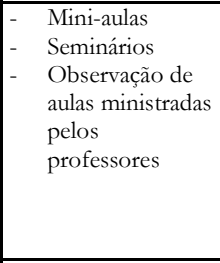 & $\begin{array}{l}\text { Professores em } \\
\text { serviço. }\end{array}$ \\
\hline \begin{tabular}{|l|} 
Ortenzi; Mateus \\
e Reis \\
$(2002)$
\end{tabular} & \begin{tabular}{|l|} 
Repensar sobre \\
crenças e \\
concepções acerca \\
do processo ensino- \\
aprendizagem e re- \\
elaboração das \\
expectativas sobre a \\
futura prática. \\
\end{tabular} & $\begin{array}{l}\text { Carter e Doyle } \\
(1995) \\
\text { Clandinin e } \\
\text { Connely (1995) }\end{array}$ & $\begin{array}{l}\text { Narrativas } \\
\text { biográficas das } \\
\text { alunas. }\end{array}$ & $\begin{array}{l}\text { Professores em } \\
\text { fase pré-serviço. }\end{array}$ \\
\hline
\end{tabular}




\section{Considerações Finais}

Os trabalhos partilham da visão comum de que a reflexão se constrói sobre a prática e permite a re-elaboração da mesma a partir de questionamentos. Enquanto que, para algumas pesquisas, a linguagem não é problematizada como promotora da reflexão, para outros ela exerce papel fundamental. Em uma visão sócio-interacional de construção de conhecimento, autores como Magalhães (2002) e Liberali (2002), por exemplo, postulam que a reflexão se constitui a partir da linguagem. Daí a importância de se propor etapas, como as sugeridas por Smyth (1992), para que as ferramentas lingüísticas constituam modos de pensar reflexivos. Em uma perspectiva crítica, é ainda enfocada a linguagem como prática discursiva sócio-histórica. Magalhães (2002) endossa a visão de que o ensino de inglês como língua estrangeira vem sendo baseado em "uma concepção apolítica e a-histórica de linguagem entendida como um 'sistema de transmissão' em detrimento de um 'sistema de significação' de idéias com relação ao mundo e a nós mesmos" (MAGALHÃES, 2002, p. 44). Ao propor programas de pesquisas colaborativos, a autora enfatiza a necessidade de se analisar como a linguagem contribui para a construção de entendimentos sobre ensino/aprendizagem na formação de professores.

Por outro lado, pesquisadores que enfocam a análise dos conteúdos têm buscado verificar se a reflexão vem acontecendo e se esta tem levado a mudanças nos modos como os professores concebem seu trabalho. Autores como Monteiro (1996), por exemplo, propõem roteiros para se julgar ações na sala de aula, ou seja, traz uma visão pré-definida de quais aspectos merecem ser objeto de análise. Assim, a reflexão seria a análise das ações com base no roteiro. Embora a prática possa estar sendo objeto de questionamento, não há como saber com que critério se possa julgar a necessidade ou não de mudança das práticas.

Deste modo, não é possível detectar de que modo conhecimentos gerados teoricamente ou na prática interagem e qual valor atribuído a eles em programas que advogam a reflexão como modo de superar práticas repetitivas e desconectadas das propostas de melhoria do ensino/aprendizagem de línguas. Em muitos projetos 
de pesquisa a distância pesquisador/pesquisado é mantida. Da mesma maneira, o julgamento sobre a eficiência do modelo reflexivo permanece com o pesquisador.

Embora uma característica deste paradigma de pesquisa seja sua vinculação direta com a prática, uma vez que o pesquisador geralmente também é formador e analisa dados de seu próprio contexto de trabalho, raramente encontramos referências explícitas ao modo como os entendimentos sobre o que seja reflexão subjazem às propostas analisadas.

A diversidade de perspectivas sobre reflexão e como ela é sedutora foi exposta com clareza por Fendler (2003, p. 20). Segundo a autora:

Today's discourse of reflection incorporates an array of meanings: a demonstration of self-consciousness, a scientific approach to planning for the future; a tacit and intuitive understanding of practice, a discipline to become more professional, a way to tap into one's authentic inner voice, a means to become a more effective teacher, and a strategy to redress injustices in society.

O mapeamento das concepções de reflexão possibilita a visualização desta diversidade, revelando a necessidade de se situar o próprio trabalho de formadores/pesquisadores dentro de diferentes vertentes, que, provavelmente, chegam a diferentes resultados.

\section{Referências Bibliográficas}

ALMEIDA FILHO, J. C. Análise de abordagem como procedimento fundador de auto-conhecimento e mudança para o professor de língua estrangeira In: - (Org.) O professor de língua estrangeira em formação. Campinas: Pontes, 1999. p. 11-28.

ASSIS-PETERSON, A. Alguns apontamentos em torno da formação de professores de língua estrangeira. Contexturas, v. 4, 1998-1999.

CASTRO, S. Teoria e prática na reconstrução da concepção de linguagem do professor de línguas. Revista Brasileira de Lingüística Aplicada, v. 2, n.1, 2002. 
CRISTÓVÃO, V. L. L. Uma experiência de reflexão e formação de professores. In: GIMENEZ, T. (Org.) Trajetórias na formação de professores de línguas. Londrina: EDUEL, 2002. p. 129-142.

CRUZ, A. A; REIS, S. O diário como instrumento de apoio na socialização de uma professora de inglês. In: GIMENEZ, T. (Org.) Trajetórias na formação de professores de línguas. Londrina: EDUEL, 2002. p. 95-108.

FENDLER, L. Teacher reflection in a hall of mirrors: historical influences and political reverberations. Educational Researcher, v. 32, n. 3, 2003. p. 16-25.

FREITAS, M. A. O movimento reflexivo subjacente a procedimentos de investigação da própria prática pelo professor de língua estrangeira. In: GIMENEZ, T. (Org.) Trajetórias na formação de professores de línguas. Londrina: EDUEL, 2002. p. 79-94.

GHEDIN, E. Professor reflexivo: da alienação da técnica à autonomia da crítica. In: PIMENTA, S. G.; GHEDIN, E. (Orgs.) Professor reflexivo no Brasil - gênese e crítica e um conceito. São Paulo: Cortez, 2002. p. $129-150$.

GRIMMETT, P. The nature of reflection and Schon's conception in perspective. In: GRIMMET'T, P. P.; ERICKSON, G. L. (Orgs.) Reflection in teacher education. New York: Teachers College Press, 1998. p. 5-16.

LEFFA, V. (Org.) O professor de línguas estrangeiras - construindo a profissão. Pelotas: Educat, 2001.

LIBERALI, F. Agente e pesquisador aprendendo na ação colaborativa. In: GIMENEZ, T. (Org.) Trajetórias na formação de professores de línguas. Londrina: EDUEL, 2002. p. 109-128.

LIBERALI, F.; ZYNGIER, S. Caderno de Reflexões, Rio de Janeiro, UFRJ, 2000.

LOUGRAN, J. J. Effective reflective practice - In search of meaning in learning about teaching. Journal of Teacher Education, v. 53, n. $1,2002$. 
MAGALHÃES, M. C. Projetos de formação contínua de educadores para uma prática crítica. The ESPecialist, v. 19, n. 2, 1998.

O professor de línguas como pesquisador de sua ação: a pesquisa colaborativa. In: GIMENEZ, T. (Org.) Trajetórias na formação de professores de línguas. Londrina: EDUEL, 2002. p. 39-58.

MONTEIRO, D. Caminhos para a reflexão do professor sobre sua prática. Contexturas, v. 3, 1996.

ORTENZI, D. I. B. G; MATEUS, E. F.; REIS, S. Alunas formandas do curso de Letras Anglo-Portuguesas: escolhas, marcos e expectativas. In: GIMENEZ, T. (Org.) Trajetórias na formação de professores de línguas. Londrina: EDUEL, 2002. p. 143-156.

PIMENTA, S. G. Professor reflexivo: construindo uma crítica. In: .; GHEDIN, E. (Org.) Professor reflexivo no Brasil gênese e crítica e um conceito. São Paulo: Cortez, 2002. p. 17-52.

SCHÖN, D.The Reflective Practitioner. New York: Basic Books, 1983.

Educating the reflective practitioner. New York: Collier Books, 1987.

SMYTH, J. Teacher's work and the politics of reflection. American Educational Research Journal, 29 (2), p. 267-300, 1992.

TELLES, J. A. A trajetória narrativa: histórias sobre a prática pedagógica e a formação do professor de línguas. In: GIMENEZ, T. (Org.) Trajetórias na formação de professores de línguas. Londrina: EDUEL, 2002. p. 15-38.

VIEIRA-ABRAHÃO, M. Teoria e prática na formação pré-serviço do professor de língua estrangeira. In: GIMENEZ, T. (Org.) Trajetórias na formação de professores de línguas. Londrina: EDUEL, 2002. p. 59-76. 
ZEICHNER, K. M. Research on teacher's thinking and different views of reflective practice in teaching and teacher education. In: CARLGREN, I.; HANDAL, G.; VAAGE, S. (Orgs.) Teacher's minds and actions - Research on Teachers' thinking and practice. London: Falmer Press, p. 9-27, 1994. 